\title{
Minireview
}

\section{The Ecology, Biology and Pathogenesis of Acinetobacter spp.: An Overview}

\author{
Hamuel James Doughari ${ }^{1 *}$, PAtrick Alois Ndakidemi ${ }^{1}$, IZANne Susan Human ${ }^{1}$, and Spinney Benade ${ }^{1}$ \\ ${ }^{1}$ Applied Sciences Faculty, Cape Peninsula University of Technology, P.O. Box 652 Cape Town 8000, South Africa \\ (Received October 9, 2010-Accepted February 16, 2011—Published online March 18, 2011)
}

\begin{abstract}
Acinetobacter are a major concern because of their rapid development of resistance to a wide range of antimicrobials, and rapid profundity in transformation, surviving desiccation and persistinge in the environment for a very long time. The organisms are associated with bacteraemia, pulmonary infections, meningitis, diarrhea and notorious nosocomial infections with mortality rates of 20 to $60 \%$. Transmission is via person-to-person contact, water and food contamination, and contaminated hospital equipment. The increasing virulence and rapid development of multidrug resistance by these organisms highlights the need to search for alternatives for chemotherapy. A poor understanding of the organisms and dearth of information about their occurrence especially in developing countries informed the need for this review paper.
\end{abstract}

Key words: Acinetobacter, acinetobactins, biofilms, coccobacilli, ecology, taxonomy

\section{Introduction}

The name "Acinetobacter" originates from the Greek word "akinetos" meaning "unable to move", as these bacteria are not motile yet they display a twitching kind of motility. Bacteria of the genus Acinetobacter have gained increasing attention in recent years first, as a result of their potential to cause severe nosocomial (Greek nosos disease, and komeion to take care of) infections $(6,7,62,63,85,108,112$, $117)$, second, for their profundity in developing multidrug (MDR) and extreme drug resistance (XDR) $(5,56,86,91$, $115)$ third, for the ability of some strains to produce verotoxins (VA) (48), and fourth, for the role members of the genus play in enhanced biological phosphorus removal in wastewater $(16,43,80)$. Recently, Acinetobacter spp. have demonstrated a hydrocarbon-degrading capability (74, 75, 122), that is of interest for soil bioremediation and a specific strain Acinetobacter baylyi ADP1 has shown remarkable competence for natural transformation irrespective of DNA source, thus making it a potentially important tool for biotechnology $(2,19,111,112)$. Possible suggested applications of Acinetobacter spp. are summarized in Table 1.

In addition, since the environment, soil, and animals are their natural habitats, food and water contamination exposes humans to infections. The ability of these bacteria to colonize almost any surface and to acquire antibiotic resistance distinguishes them from other infectious bacteria. Despite the huge increase in the frequency of infections caused by MDR Acinetobacter, there is still a lack of awareness of the importance of these microorganisms (30). This review therefore gives an overview of the biology, ecology and medical significance of the entire genus Acinetobacter in a broad sense with a view to providing basic general information on this group of bacteria for a better understanding and the possible adoption of proactive and effective control measures against infections associated with some of the bacteria.

\footnotetext{
* Corresponding author. E-mail: jameshamuel@yahoo.com;
}

Tel: +27-7-3355-0274, Fax: +234-703-559-9712.

\section{Recent taxonomy}

The first strain of Acinetobacter spp. was isolated from soil and identified as Micrococcus calcoaceticus by Beijerinck in 1911 (2, 13). Acinetobacter group were previously insufficiently defined for a very long time and confusedly classified into more than a dozen different genera (Achromobacter, Alcaligens, Cytophaga, Diplococcus, Bacterium, Herellea, Lingelsheimia, Mima, Micrococcus, Moraxella and Neisseria) (2, 15, 27, 90, 97).

The genus Acinetobacter was first created in 1954 by Brisou and Prevot to separate the non motile from the motile members of the tribe "Achromobactereae" and was composed of non-pigmented Gram-negative saprophytic bacteria comprising both oxidase-negative and oxidase-positive species. In 1957, Brisou identified a typical species named Acinetobacter anitratum (15). Baumann et al. (3) using distinct nutritional properties later characterized the organisms as oxidase-negative and proposed to classify them under the genus Acinetobacter. In 1971, the subcommittee on Moraxella and allied bacteria accepted this proposal and the genus was limited to oxidase-negative strains (71). Three species were initially included in this genus but because of difficulties in distinguishing them based on differences in physiological characteristics, all the species were named A. calcoaceticus (2). In fact, Bergy's Manual of Bacteriology placed these bacteria in the family Neisseriaceae with only $A$. calcoaceticus as a species and the two subspecies A. anitratum and Acinetobacter lwofii (59). Several years later, Bouvet and Grimont (12) identified more than fifteen genomic species, including Acinetobacter baumannii (formerly A. calcoaceticus var anitratum and A. glucidolytica non liquefaciens), Acinetobacter haemolyticus, Acinetobacter junii, Acinetobacter johnsonii and Acinetobacter radioresistens $(12,13,27)$.

The species' names have undergone considerable taxonomic changes over the years as molecular methods have advanced understanding of the genetic make-up of this group of organisms (109). Recent classifications which seem 
Table 1. Possible applications for Acinetobacter spp. and their products

\begin{tabular}{|c|c|c|c|c|}
\hline $\begin{array}{l}\text { Bioremediation of } \\
\text { waste waters and } \\
\text { effluents }\end{array}$ & $\begin{array}{l}\text { Bioremediation of soils and } \\
\text { effluents contaminated } \\
\text { with heavy metals }\end{array}$ & $\begin{array}{l}\text { Production of biopolymers } \\
\text { and biosurfactant }\end{array}$ & Biomass production & Clinical uses \\
\hline i) Phosphate removal & $\begin{array}{l}\text { i) Textile or tannery industrial } \\
\text { effluent containing heavy } \\
\text { metals }\end{array}$ & $\begin{array}{l}\text { i) For prevention of dental } \\
\text { plaque }\end{array}$ & i) Protein production & $\begin{array}{l}\text { i) Production of } \\
\text { glutaminase-sparaginase }\end{array}$ \\
\hline $\begin{array}{l}\text { ii) Degradation of } \\
\text { petrochemicals }\end{array}$ & $\begin{array}{l}\text { ii) Lead from digested } \\
\text { sewage sludge }\end{array}$ & $\begin{array}{l}\text { ii) For use in paper-making } \\
\text { and other industries }\end{array}$ & $\begin{array}{l}\text { ii) Manganese leaching } \\
\text { from ores }\end{array}$ & $\begin{array}{l}\text { ii) Production of } \mathrm{L}(-) \\
\text { carnitine }\end{array}$ \\
\hline $\begin{array}{l}\text { iii) Breakdown of } \\
\text { organic pollutants }\end{array}$ & $\begin{array}{l}\text { iv) Silver contaminated } \\
\text { photographic wastewater }\end{array}$ & $\begin{array}{l}\text { iv) For incorporation in } \\
\text { cosmetics, detergents and } \\
\text { shampoos }\end{array}$ & & \\
\hline
\end{tabular}

$(82,107)$

to have gained wide acceptance among bacterial taxonomists have recognized this group of heterogeneous bacteria as gamma proteobacteria classified in the order Pseudomonadales and the family Moraxellaceae (13). Thus the taxonomical classification is given as; Domain-Bacteria, Phylum-Proteobacteria, Class-Gammaproteobacteria, Order-Pseudomonadales, Family-Moraxellaceae, Genus -Acinetobacter (DNA G+C content 39-47\%) and species (with A. baumannii, A. haemolyticus and A. calcoaceticus as species of clinical importance). Recent classifications using cell shape, absence of flagella, $\mathrm{G}+\mathrm{C}$ content of DNA and nutritional properties, placed these organisms ( $A$. baumannii, A. haemolyticus and A. calcoaceticus as well as other Acinetobacters) in the genus Moraxella, now known as Acinetobacter (2). Based on DNA-DNA hybridization studies, 32 species of Acinetobacter have now been recognized, with 22 assigned valid names and the rest assigned numbers and referred to as a 'genomic group' $(42,91)$. Among the named species, $A$. baumannii is the main species associated with clinical infections followed by the non- $A$. baumannii species $A$. haemolyticus, $A$. junii, A. johnsonii and $A$. lwofii $(2,49)$. Recently, the emergence of other species of clinical importance such as $A$. ursingii and $A$. schindleri has been reported (95).

Another difficulty associated with classification is the close resemblance between species such that phenotypic differentiation becomes very difficult. For instance, there is a close relationship between A. baumannii and A. calcoaceticus, and genomospecies 3 and 13. As a result of the difficulties in distinguishing isolates phenotypically in the former pair, the term A. baumannii-A. calcoaceticus complex or $A b c$ complex has been used. Furthermore, some authors still report these isolates as A. calcoaceticus subspecies anitratum. This situation led to contributors to the Manual of Clinical Microbiology to conclude that the majority of species of this group of bacteria cannot be reliably distinguished based on phenotypic tests $(13,37,94,102)$.

To avoid confusion therefore, a more reliable classification based on combination of the results of DNA-DNA hybridization and on phenotypic characteristics was adopted (2). In clinical practice however, these taxonomic complications have led to the under-recognition and misclassification of the species.

\section{Biology, cultural and biochemical characteristics of the Acinetobacter group}

The genus Acinetobacter consists of strictly aerobic, nonmotile, catalase-positive, indole-negative, oxidase-negative, Gram-negative, non-fermentative encapsulated coccobacilli rods $(13,111)$. Many strains are unable to reduce nitrates to nitrites (9). The bacteria are strictly aerobic and although they flourish on most laboratory media at temperatures of $20-30^{\circ} \mathrm{C}$ with the clinical isolates growing at 37 to $42^{\circ} \mathrm{C}$, for most strains the optimum temperature is $33-35^{\circ} \mathrm{C}$. In the exponential phase of growth, they are bacilli 0.9 to $1.6 \mu \mathrm{m}$ in diameter and 1.5 to $2.5 \mu \mathrm{m}$ in length, often in pairs or assembled into longer chains of varying length. Acinetobacter spp. are non-fastidious and can be grown on standard laboratory media (64). On blood agar (BA), colonies show typical morphology and size: Non-pigmented, white or cream colored, smooth or mucoid (when capsule is present), opaque, 1-2 $\mathrm{mm}$ in diameter (after $18-24 \mathrm{~h}$ incubation at $37^{\circ} \mathrm{C}$ ) (9), on eosin methylene blue agar (EMB), colonies are bluish to bluish gray, on Herellea agar (HA) they are pale lavender in color (9), while on Leeds Acinetobacter Medium (LAM) the bacteria are pink on a purple background. In aged cultures the bacteria may be spherical or filamentous. The organisms can be recovered after enrichment culture from virtually all samples obtained from soil or surface water (85). The members of the Acinetobacter group are nutritionally versatile chemoheterotrophs and the range of substrates they use as sole carbon and energy sources parallels that of the aerobic pseudomonads.

The cell wall of Acinetobacter is typical of that of Gramnegative bacteria, however de-staining is difficult due to a tendency to retain crystal violet and this can lead to incorrect identification as Gram-positive cocci (1). The cells of Acinetobacter vary in size and arrangement. Acinetobacter generally form smooth and sometimes mucoid colonies on solid media, ranging in color from white to pale yellow or grayish white. Some environmental strains have been reported to produce a diffusible brown pigment $(1,85)$. Several clinical isolates show hemolysis on sheep blood agar plates (85).

\section{Pathogenesis, virulence factors and resistance}

Pathogenesis. In the past, Acinetobacter spp. were con- 
sidered saprophytes of little clinical significance (7), but with the introduction of powerful new antibiotics in clinical practice and agriculture and the use of invasive procedures in hospital intensive care units (ICUs), drug resistant-related community and hospital-acquired Acinetobacter infections have emerged with increasing frequency (49). A. baumannii is an important emerging nosocomial pathogen worldwide, followed by $A$. lwofii and $A$. haemolyticus. Conditions attributable to Acinetobacter spp. include blood stream infections (BIs), ventilator-associated pneumonia (VAP), bacteremia, meningitis, urinary tract infections, cholangitis, peritonitis, skin and wound infections, ventriculitis, and infective endocarditis $(10,56,117)$. The bacteria can also colonize the skin and respiratory tract without causing an infection. An infection results if the host first line of defence is compromised. Studies have however, revealed that colonization increased with hospital stays (82). In gastroentistenal infections with $A$. lwoffii and $H$. pylori infections for example, the normal tissue architecture of the gastric epithelium is altered leading to chronic gastritis (Fig. 1). Infections with $A$. lwoffii induce production of pro-inflammatory cytokines which increase gastrin levels that in turn promote proliferation of the gastric epithelium. Persistent inflammation including the activation of antigen-presenting cells (APCs), release of pro-inflammatory cytokines such as macrophage chemotactic protein (MCP), macrophage inflammatory protein (MIP), Toll-like receptor (TLR), somatostatin (SOM), reactive oxygen species (ROS) involved in acid secretion (Fig. 1) and changes in the number of gastric epithelial cells can lead to gastritis, peptic ulcers, and more rarely, gastric cancer (94). Though colonization occurs more frequently than infections, studies have also shown that lethal infections result from pathogenic strains in immunosuppressed animals with mortality rates of 75 to $100 \%$ (96). The bacteria have also been associated with bacteremia, sepsis in neonatal intensive care units and pediatric oncology units, as well as community acquired meningitis and endophthalmitis (25, $106,110)$. Other conditions include suppuration; abscesses of the brain, lung, and the thyroid, secondary infections of

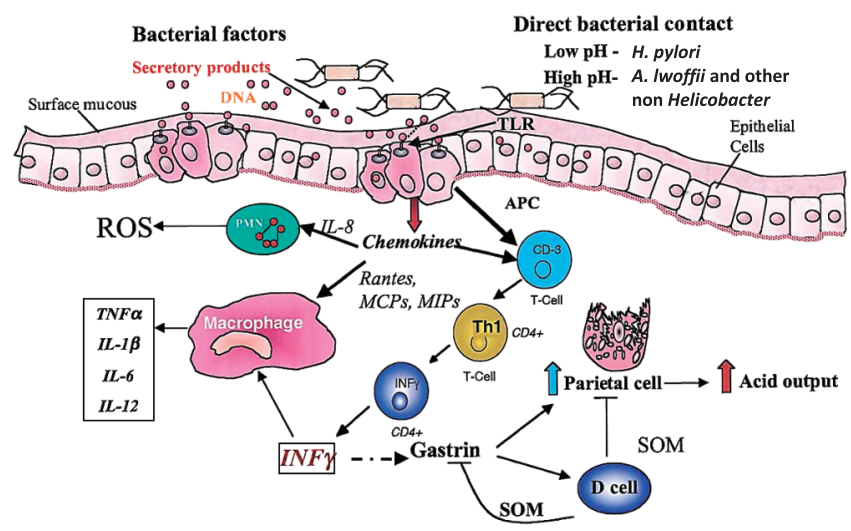

Fig. 1. Schematic model of bacterial colonization of the gastric mucosa, activation of antigen presenting cells (APC), release of proinflammatory cytokines and alteration in the number of gastric epithelial cells involved in acid secretion. MCP, macrophage chemotactic protein; MIP, macrophage inflammatory protein; TLR, Toll-like receptor; SOM, somatostatin; ROS, reactive oxygen species (92). (Reproduced with permission, copyright Elsevier). wounds or surgical trauma, and purulent lesions of the eye. The organisms are ranked 9th after S. aureus, E. coli, Klebsiella spp. P. aerugenosa, C. albicans, Enterococci, Serratia and Enterobacter as agents of nosocomial BIs, and account for $34 \%$ of the mortality and $43 \%$ of deaths due to hospital-acquired infections (29). They are the second most commonly isolated nonfermenters in human specimens (81), after Pseudomonas aeruginosa and their incidence is on the increase and mortality rates are quite high $(56,111,119)$. $A$. baumannii was found to be associated with a series of fatal cases of community pneumonia (29) and A. haemolyticus, with endocarditis and verotoxin production, and hence bloody diarrhea $(11,17,47)$.

Pathogenic mechanisms. The pathogenic mechanisms of Acinetobacter spp. are little understood or studied (84). Though the infective doses of Acinetobacter in human infections have yet to be determined, intraperitoneal injections in mice with 40 clinical isolates of Acinetobacter showed the $\mathrm{LD}_{50}$ to range from 103 to 106 viable cells per mouse (82). Though $A$. baumannii is the most studied species, the precise mechanisms involved in the establishment and progression of infections by this species are unclear. The organism is not known to produce either diffusible toxins or cytolysins, and few virulence factors have been identified (45). However, comparative genomic studies with $A$. baumannii and the environmental $A$. baylyi have identified genes involved in pilus biogenesis, iron uptake and metabolism, quorum sensing and a type IV secretion system as making up part of the organism's 'virulome' $(106,111)$. Other authors have also reported common virulence factors among the Acinetobacters which are discussed below. There is a need for microbiologists to further investigate these virulence mechanisms for possible discovery of more effective control measures.

Virulence factors. i) Cell surface hydrophobicity and enzymes: Acinetobacter spp. have been demonstrated to exhibit cell surface hydrophobicity, an important determinant bacterial adhesion. For a successful infection to occur, bacteria must successfully adhere to host cells (24). The hydrophobicity of a microorganism protects it from being phagocytosed and appears to play an important role in its attachment to various polymers. Hydrophobicity also confers the ability to adhere to plastic surfaces, such as catheters and prostheses. Through this hydrophobicity, Acinetobacter spp. coaggregate into flocs in sludge. Non-flocculating $A$. johnsonii S35 displays significant coaggregation with three other bacterial species, Oligotropha carboxidovorans, Microbacterium esteraromaticum, and Xanthomonas axonopodis (76). The degree and mechanism of coaggregation were found to be pair-dependent; and cell surface hydrophobicity was an important factor controlling the coaggregation of $A$. johnsonii S35 and its partner strains (76, 89). The hydrophobic properties of bacterial strains depend on their surface structure, which in turn determines the degree of hydrophobicity: the rougher the cell surface, the greater the hydrophobicity and vice versa. In Acinetobacter, the presence of protein protrusions on the cell surface confers hydrophobicity. A recent study using scanning electron microscopy showed the presence of blister-like protein protrusions on A. johnsonii S35 and A. junii S33, these bacterial 
cells were able to coaggregate efficiently with other bacterial cells compared to a mutant strain A. johnsonii IAM1517 with smooth cell surfaces (89) which was unable to form aggregates (89).

Surface hydrophobicity is also mediated by colonization factors, complimentary cell surface receptors, fimbriae and other cell wall components $(14,60)$ and cell surface enzymes that facilitate the adhesion of bacterial cells to host cells. For example, the urease activity of Acinetobacter promotes colonization of the mouse stomach (24). Urease also helps Acinetobacter spp. colonize the hypochlorhydric or achlorhydric human stomach inducing inflammation (100). Polysaccharide slimes on the bacterial cell surface are reported to confer hydrophobicity $(53,6193,97)$. Other virulenceconferring enzymes secreted by the bacteria include esterases, certain amino-peptidases, and acid phosphatases $(93,108)$. Esterases have strong hydrolyzing activity against shortchain fatty acids, thereby causing damage to lipid tissues. Hydrolytic enzymes usually confer the bacterium with very strong hemolytic activity. The most extensively studied hydrolytic enzymes in Ps. aerugenosa are phospholipases C (PLC)-H, which is encoded by $p l c S$, is acidic and has strong hemolytic activity, and PLC-N, which is encoded by plcN, is basic, and has no hemolytic activity (93). Recent studies revealed that two copies of the phospholipase $\mathrm{C}(\mathrm{plc})$ gene with $50 \%$ identity to that of Pseudomonas are found in $A$. baumannii. It is therefore assumed that these lipases serve a similar function, although this is yet to be elucidated (111). Hoštacká and Klokočníková also reported the secretion of phosphotidylethanolamine and sphingomyelin which are all cytotoxic to leucocytes (53).

ii) Toxic slime polysaccharides: Toxic slime polysaccharides have also been reported among Acinetobacter spp. (53). They are usually produced during the exponential phase of growth and are made up of the glucose building blocks Dglucuronic acid, D-mannose, L-ramnose and D-glucose. The slime polysaccharides are toxic to neutroplils, and inhibit their migration as well as inhibit phagocytosis, but without disrupting the host immune system $(50,53)$. It is important to understand these structures in order to develop effective control measures. Currently, the authors are focusing on determining the hydrophobicity of $A$. haemolyticus isolates from water and wastewater samples and the effect of stress and phytochemical extracts on this hydrophobicity.

iii) Verotoxins: Grotiuz et al. (47) first reported the production of verotoxins in Acinetobacter (from $A$. haemolyticus). Verotoxins are associated with bloody diarrheas and produced by many enteric bacteria including $E$. coli and Shigella dysenteriae (31). The toxins belong to a particular protein subfamily, the RNA $N$-glycosidases which directly target the cell ribosome machinery, inhibiting protein synthesis. Verotoxins can be classified into 2 antigenic groups, vtx-1 and vtx-2, which include (especially vtx-2) an important number of genotypic variants. The mechanism by which $A$. haemolyticus produces this toxin is, however, not well understood. Lambert et al. (65) speculated that $A$. haemolyticus acquires vtx2-producing activity via horizontal gene transfer in the gut lumen, since it can be rapidly transformed. In any case, the pathogenicity, basic structure, and chemical components of the toxins are the same as those of verotoxins from E. coli and other bacteria (65). The emergence of verotoxin-producing $A$. haemolyticus strains is worrisome given the high transformability of Acinetobacter spp. This therefore calls for intensive surveillance of these organisms especially in the environment for the development of proactive control measures. The current work therefore focuses on isolation and identification of A. haemolyticus from environmental samples and the determination of their verotoxin production and antimicrobial resistance profiles as well as the effect of phytochemical extracts on verotoxin production by the isolates.

iv) Siderophores: Siderophores are host iron-binding protein structures responsible for iron up take in bacteria. One possible defense mechanism against bacterial infections is the reduction of free extracellular iron concentrations via iron-binding proteins such as lactoferrin or by transfer (14, 121). The normal concentration of free iron in the body is $10^{-8} \mathrm{M}$, and the concentration required for bacteria to survive in the human body is $10^{-6} \mathrm{M}$. Bacteria meet their iron requirement by binding exogenous iron using siderophores or hemophores $(61,72,121)$. Bacterial siderophores are called aerobactins. Acinetobacter siderophores are called acinetobactins and are chiefly made up of the amine histamine which results from histidin decarboxylation (78). Iron import into the bacterial cell is however regulated by a ferric regulator uptake protein serving as a transcription repressor to induce siderophore synthesis or degradation (111).

v) Outer membrane proteins (OMPs): Outer membrane proteins (OMPs) in some Gram-negative bacteria are known to have essential roles in pathogenesis and adaptation in host cells as well as in antibiotic resistance. Several OMPs of the OmpA family have been characterized in various Acinetobacter strains $(28,45)$. Vila et al. (115) reported homology between the genome sequence of OmpA of $A$. radioresistens, $A$. baumannii and $A$. junii. The OmpA proteins induce apoptosis of epithelial cells (21), stimulating gastrin and interlukin B gene expression (55). In a recent study, Vallenet et al. (111) showed that A. baylyi OmpA has emulsifying activity and that only one gene in each Acinetobacter strain encodes an OmpA protein. In other words, these proteins share more than $89 \%$ of their amino acids and thus have the same chromosomal context. The cells of Acinetobacter spp. are surrounded by OmpA, a protein to kill host cells (20). During an infection, OmpA binds to eukaryotic cells and gets translocated into the nucleus where it causes cell death $(20,28,99)$.

Resistance to antibiotics and mechanisms of resistance. The major problem with Acinetobacter spp. is their resistance to antibiotics $(66,67)$. Savov et al. (101) reported that these organisms are most commonly resistant to ampicillin, cephalothin, carbenicillin, gentamicin, amikacin, chloramphenicol, tetracycline, co-trimoxazole, ciprofloxacin and cefoperazone. Previously ampicillin, second generation cephalosporins, quinolones, minocyline, colistin, amynoglycosides, impenim, sulbactam and gentamicin were used to treat Acinetobacter infections. Resistance to these antibiotics has hindered therapeutic management, causing growing concern the world over $(32,47,87,91,115)$. A. baumannii has been developing resistance to all antibiotics used in treating infections. Currently, most $A$. baumannii strains are resistant 
to aminoglycosides, tetracyclines, cephalosporins, ampicillins, cefotaximes, chloramphenicols, gentamicins and tobramycins (91). The activity of carbapenems is further jeopardized by the emergence of enzymatic and membrane-based mechanisms of resistance (85).

Antimicrobial resistance among Acinetobacter is either intrinsic or acquired via transformation. Several mechanisms of resistance including altered penicillin-binding proteins, low/decrease permeability of the outer membrane to antibiotics or increase in the active efflux of the antibiotics, target site mutations, and inactivation via modifying enzymes have been reported $(56,115)$. Mechanisms of resistance to antibiotics by Acinetobacter spp. vary with species, the type of antibiotic, and geographical location (56). Thus $\beta$-lactam antibiotics are inactivated by the production of $\beta$-lactamases or alterations of penicillin-binding proteins and decreased permeability of the outer membrane to $\beta$-lactams (92); cephalosporins by chromosomally encoded cephalosporinases and occasionally, by cell impermeability and aminoglyco- sides via aminoglycoside-modifying enzymes; quinolones by altering the target enzymes DNA gyrase and topoisomerase IV through chromosomal mutations, a decrease in permeability and increase in the active efflux of the drug by the microbial cell (67). Several efflux pumps acting against antibiotics have been described for Acinetobacter spp. grouped as (i) major facilitator superfamilies (MFSs) comprising the Tet (A)-efflux system for tetracycline, Tet (B)-efflux system for tetracycline and minocycline and Caml A-efflux system for chloramphenicol, (ii) resistance-nodulation division (RND) comprising Ade ABC (ATP binding cassettes) — efflux systems against aminoglycosides, $\beta$-lactams, chloramphenicol, erythromycin, tetracyclines, ethidium bromide, and reduced susceptibility to fluoroquinolones and (iii) multi drug and toxic compounds extrusion systems (MATEs) comprising of Abe $\mathrm{M}$ - efflux system against norfloxacin, ofloxacin, ciprofloxacin, gentamicin, 4,6-diamino-2-phenylindole (DAPI), triclosan, acriflavin, doxocrubicin, rhodamin $6 \mathrm{G}$ and ethidium bromide (114). Major mechanisms of resistance to dif-

Table 2. Major mechanisms of resistance identified for the different classes of antibiotics

\begin{tabular}{|c|c|c|}
\hline $\begin{array}{c}\text { Antimicrobial class/resistance } \\
\text { mechanism }\end{array}$ & Class/family & Variants \\
\hline \multicolumn{3}{|l|}{$\beta$-Lactam } \\
\hline \multirow{4}{*}{$\beta$-Lactamases } & Intrinsic cephalosporinase & $\mathrm{AmpC}(\mathrm{ADC} 1-7)$ \\
\hline & Class A/high-prevalence $\mathrm{ESBL}_{\mathrm{A}}$ & $\begin{array}{l}\text { VEB-1, -2, PER-1, -2, TEM-92, -116, } \\
\text { SHV-12, -5, CTX-M-2, -3 }\end{array}$ \\
\hline & Class A/low-prevalence ESBL $\mathrm{A}_{\mathrm{A}}$ & $\mathrm{SCO}-1$ \\
\hline & Class D OXA enzymes/ESBL $\mathrm{M}_{\mathrm{M}-\mathrm{D}}$ & OXA-51-like \\
\hline \multirow[t]{3}{*}{ Carbapenemases } & Class D OXA enzymes/ESBL CARBA-D, $_{\text {, }}$ & OXA-23-27, -37, -40, -58- \\
\hline & MBLs/ESBL & like, VIM, IMP, SIM \\
\hline & Class A carbapenemase/ESBL ${ }_{C A R B A-A}$ & GES-11 \\
\hline OMP loss & CarO, HMP-AB, 33-36 kDa protein, $43 \mathrm{kDa}$ protein & \\
\hline Efflux pump & AdeABC & \\
\hline Altered PBP expression & & PBP2 downregulation \\
\hline \multicolumn{3}{|l|}{ Tetracyclines } \\
\hline Efflux pump & MFS, RND & A, TetB, AdeABC \\
\hline Ribosomal protection & & TetM \\
\hline \multicolumn{3}{|l|}{ Glycylcyclines } \\
\hline Efflux pump & RND & AdeABC \\
\hline \multicolumn{3}{|l|}{ Aminoglycosides } \\
\hline \multirow[t]{3}{*}{ Enzymatic degradation } & Acetyltransferases & AacC1/2, AadA, AadB \\
\hline & Nucleotidyltransferases & Ant1 \\
\hline & Phosphotransferases & $\begin{array}{l}\text { AphA1, AphA6, } \\
\text { ArmA }\end{array}$ \\
\hline \multicolumn{3}{|l|}{ Ouinolones } \\
\hline DNA gyrase/topoisomerase mutations & & GyrA/ParC \\
\hline Efflux pumps & RND, MATE, BIMP & AdeABC, AdeM, AbeS \\
\hline \multicolumn{3}{|l|}{ Chloramphenicol } \\
\hline \multirow[t]{3}{*}{ Efflux pumps } & RND & AdeABC, AdeIJK \\
\hline & MFS & $\mathrm{CmlA}, \mathrm{CraA}$ \\
\hline & BIMP & AbeS \\
\hline \multicolumn{3}{|l|}{ Trimethoprim/sulfamethoxazole } \\
\hline Efflux pump & RND & AdeABC, AdeIJK \\
\hline Dihydropteroate synthase & & SulI/II \\
\hline Dihydrofolate reductase & & FolA \\
\hline \multicolumn{3}{|l|}{ Macrolides } \\
\hline Efflux pumps & MATE, BIMP & AbeM, AbeS \\
\hline Polymyxins & PmrAB two-component mutation & \\
\hline
\end{tabular}

MBL — metallo- $\beta$-lactamase; OMP—outer membrane protein; HMP—-heat modifiable protein; PBP—penicillin-binding protein; MFS—-major facilitator superfamily; RND—resistance-nodulation-cell division; MATE—multidrug and toxic compound extrusion; BIMP—bacterial integral membrane proteins (46). 
ferent classes of antibiotics are listed in Table 2.

Owing to this escalation of multidrug resistance, deliberate efforts should be made towards investigating other sources of antibiotics with novel mechanisms of action, with a view to developing effective control measures against the recalcitrant bacteria. Investigations of phytochemicals should be considered since they form a very rich source of antibiotic substances (32) with potential activity against microbial pathogens.

Resistance to environmental and host factors. The emergence of nosocomial or community-acquired infections of Acinetobacter is a result of high adaptability to adverse environmental conditions, an ability to persist for several days in dry and harsh environments such as the hospital environment, the increased use of broad spectrum antibiotics, the vulnerability of individuals or patients, and the rapid transformation of organisms that results in increased multidrug resistance. To survive and multiply in the host, many bacteria produce a variety of substances that allow them avoid the defense mechanisms of the host (58). Acinetobacter spp. are found as natural inhabitants of human skin and repeated isolation may suggest that they are potential pathogens. Acinetobacter spp. are able to survive on moist and dry surfaces (118) and some strains have been found to be tolerant of soap $(9,56)$. The ability of Acinetobacter to persist in dry conditions, on inanimate objects, and in dust for several days and weeks has been reported. Recent isolates of $A$. lwoffii compared to the isolates from the 1970 s are relatively resistant to irradiation. This raises concerns about the persistence of $A$. lwoffii on medical devices that are sterilized by gamma irradiation, especially in intensive care units (ICU) (93).

Acinetobacter species also survive exposure to the commonly used disinfectants like chlorhexidine, gluconate and phenols, particularly those not used in the appropriate concentrations (40). Compared with other genera of Gramnegative bacilli, Acinetobacter is able to survive much better on fingertips or on dry surfaces when tested under simulated environmental conditions (118). Apart from being able to grow at a very broad range of temperatures, they are also able to resist drying. The presence of more electron dense cell walls and nucleic acids are thought to be responsible for the heat $\left(50-75^{\circ} \mathrm{C}\right)$ resistance $(56)$. In fact, while $P S$. aerugenosa and $E$. coli can only survive heat for a maximum of $24 \mathrm{~h}$, A. baumannii can survive for up to 25 days (58). Survival for 157 days (A. radioresistens), over 30 days ( $A$. baumannii) and 21 days ( $A$. lwoffii) has been reported (54, 57, 88). A. baumannii has also demonstrated resistance to the killing action of normal human serum (NHS) and the possession of a lipopolysaccharide was thought to be partly responsible (42). King et al. (61) also suggested modulation of pathogen interaction with serum by a complement regulator. The complement system is the host innate immune defense comprising a series of serum proteins that initiates the death of the bacterium through either lysis or opsonization. One of the mechanisms by which bacterial cells resist killing by serum compliments is by producing surface proteins that bind human factor $\mathrm{H}(\mathrm{FH})$, and thereby inhibit the deposition of complements on the bacterial surface $(41,63)$. The mechanism by which Acinetobacter spp. resist serum compliments is however yet to be discovered.

\section{Transfer of resistance among Acinetobacter spp.}

Resistance to antibiotics is transferred among Acinetobacter spp. via plasmids and transposons. While plasmids are DNA elements that carry antibiotic and heavy metal resistance conferring genes capable of autonomous replication, transposons are sequences of DNA that can move (or transpose) themselves to new positions within the genome of a bacterium (or any other prokaryotic cell). These elements are often present in resistant bacteria and have been reported in clinical isolates of Acinetobacter spp. (40). Plasmids and transposons are easily transferred between bacteria via the process of genetic transformation. Transformation occurs between Acinetobacter spp. Due to the high frequency and degree of adaptability and transformability among some strains of Acinetobacter spp., species capable of colonizing multiple settings can mediate the transfer of novel antibiotic resistance genes from antibiotic-producing environmental species to clinical isolates. For example, an intermediate group including spp. 7,8 , and 9 is capable of adapting to human tissues as well as remaining in the environment thus serving as effective vehicles for conveying resistance genes between species (93). Gene transfers in Acinetobacter spp. also occur via conjugation and transduction. Conjugation in Acinetobacter involves a wide host range and chromosomal transfer, while transduction involves a large number of bacteriophages with a restricted host range (93). Owing to the high transformation ability of Acinetobacters, the role of genetic elements in the virulence of this group needs to be thoroughly investigated and adequately understood as in the case of E. coli. This will no doubt open up more frontiers for more effective control measures and the application of the organisms in biotechnology.

\section{Epidemiology and ecology}

Several studies have reported the epidemiology of $A$. baumannii infections in different parts of the world including Europe, the United States and South America (64, 104). Although these organisms are often associated with nosocomial (117) infections, community acquired diarrhea outbreaks and pneumonia have been reported with some frequency in tropical regions of the world especially during warm (summer) and humid months $(18,56)$. An infrequent manifestation of Acinetobacter is nosocomial meningitis and these cases have been reported after neurosurgical procedures $(18,56,58)$. The morbidity and mortality rates of Acinetobacter infections are comparable to those of methicillin-resistant Staphylococcus aureus (MRSA), and the organisms have been termed 'Gram-negative MRSA', manifesting similar epidemiological behavior to MRSA. The impact in terms of morbidity and mortality is probably closer to that of coagulase-negative staphylococci and available data suggest that the mortality rate ranges from $20 \%$ to $60 \%$ (58). Thus several reports have alerted clinicians to the emergence of a potentially difficult and dangerous organism that is responsible for outbreaks of infection and can cause severe problems (58). Owing to the morphological 
similarity between Acinetobacter and Neisseriaceae (both being Gram-negative diplococci), care should be taken while examining the Gram stain. Neisseria meningitidis is, however, far more common as an agent of meningitis. Uncommon conditions involving Acinetobacter are contiguous osteomyelitis, peritonitis associated with continuous ambulatory peritoneal dialysis, ophthalmic infection, skin and wound infections, abscesses, sepsis, endocarditis and burn infections. Despite the increasing significance of Acinetobacter, there are no significant epidemiological reports on the incidence of infections from many parts of the world particularly, developing countries. Epidemiologic investigations on Acinetobacter spp. of clinical significance other than $A$. baumannii as well as on the epidemiology of acinetobacteriosis in developing countries are essential.

Acinetobacters are mostly free living saprophytes found ubiquitously in nature (111). However, different species of the genus are generally associated with different habitats. Acinetobacter genomospecies 3 is found in water and soil, on vegetables, and on human skin; $A$. johnsonii and $A$. haemolyticus are found in water, wastewater, soil, on human skin, and in human feces; $A$. lwoffii and $A$. radioresistens are found on human skin; and Acinetobacter genomic species 11 is found in water, in soil, and on vegetables as well as the human intestinal tract $(10,26)$.

Human and animal body. Acinetobacter spp. are generally considered part of the normal flora of the skin and mucous membranes or the pharynx, human respiratory secretions, urine, rectum (116) and other human clinical samples (101). They are the only group of Gram-negative bacteria that may be natural residents of human skin, with carriage rates of $42.5 \%$ in healthy individuals and as high as $75 \%$ in hospitalized patients (101). In a study conducted by Seifert et al. (103) Acinetobacter spp. were isolated from various parts of the human body including the forehead, nose, ear, throat, trachea, conjunctiva axilla, hand, groin, vagina, perineum and toe web. The organisms are also found in the distal urethra of healthy people (63). Generally the species most frequently isolated are A. johnsonii, $A$. lwoffii, A. radioresistens, A. baumannii, A. calcoaceticus, A. haemolyticus and Acinetobacter genomospecies 3 and 13. Colonization of the intestinal tract by Acinetobacter spp. however, is controversial. While some authors suggest that it is an unusual event (46), others report that the gastrointestinal tract is the most important reservoir of resistant strains (23). The difference is probably due to the epidemiological situation i.e. whether there is an epidemic outbreak or not.

Acinetobacter spp. have been isolated from different animal sources including birds; fish and rainbow trout (10, 49). On several occasions, chicken septicemia (15\% death rate), septicemia in turkeys and calves, mastitis and metrititis in cows, abortions in cattle, pigs and horses, keratoconjunctivitis in cattle, omphalitis in calves, ear infections in cats, and respiratory infections and Balanoposthitis in horses have been reported (38). A. beijerinkii and A. baumannii are among the species of Acinetobacter implicated in animal diseases (38). The organisms have also been isolated from lice collected from homeless people (68).
Food contamination. Acinetobacter spp. have been associated with food contamination. Several foods including vegetables have long been known to be an important source of contamination with Gram-negative bacteria such as Escherichia coli and Klebsiella spp. (85). Acinetobacter spp. have been recovered from vegetables, apples, melons, cabbages, cauliflowers, lettuce, cucumbers, peppers, mushrooms, radishes, carrots as well as tubers such as potatoes and cereals such as sweet corn $(10,85)$. Acinetobacter spp. have also been implicated in the spoilage of bacon, chicken, meat, fish and eggs even when stored under refrigeration or after adequate gamma irradiation $(84,108)$. Hospital food could also be a potential source of $A$. baumannii $(10,108)$. Many strains isolated from foods have lipolytic activity and some strains produce diffusible pigments.

Soil and wastewaters. Water and soil also provide a home to various microorganisms. Acinetobacter genomospecies 3, A. baumannii, A. calcoaceticus acinetobacters, and $A$. calcoaceticus, A. johnsonii, A. haemolyticus, and Acinetobacter genomic species 11 have been reported to inhabit soil and aquatic environments (86). The organisms have also been isolated from freshwater ecosystems; raw sewage and wastewater treatment plants (10) and activated sludge (16, 83, 85). A. baylyi, A. bouvetii, A. grimontii, A. tjernbergiae, A. towneri, and A. tandoii are commonly found in natural environments but occasionally isolated in activated sludge and have not been found associated with humans $(19,85)$. They are able to store phosphate as polyphosphates and may have potential applications in the biological removal of phosphates (2).

Biofilms. Biofilms are composed of microorganisms attached to surfaces and encased in a hydrated polymeric matrix made of polysaccharides, proteins and nucleic acids $(100,113)$. Biofilms function in a manner similar to tissues, using a primitive circulatory system to pump fluids and nutrients through channels in the matrix by changing the ionic strength of the extracellular milieu, causing periodic contraction of matrix polymers.

Pilus mediated biofilms (PMBs) are formed by Acinetobacter spp. especially A. baumannii, A. haemolyticus, A. lwoffii and $A$. calcoaceticus thus forming thin layers of microorganisms on glass, medical devises, metals, ceramics and other inanimate objects $(28,39)$. The biofilm thus constitutes a colonial niche for the bacteria from where contact with humans will result in infection. The hydrophobic surface polysaccharide and pili on the bacterial cell surface initiates adherence to human epithelial cells thus initiating the infection process (28).

Life in biofilms provides microbes with protection against assault from the outside world with barriers against penetration by antimicrobial agents, oxygen and nutrients, along with depressed growth rates and an activated adaptive stress response (99). It also enables the organisms to resist the immune host response. Vidal et al. (90) and Lee et al. (113) reported the readiness of $A$. baumannii to adhere to both biological and abiotic surfaces, on which it is able to form biofilms thus ensuring its survival $(69,112)$.

Unlike in other bacteria where the formation of biofilms is facilitated by intrinsic factors such as the presence of type IV pili, flagella, curli and fimbriae, in Acinetobacter spp., 
putative chaperon secretion membrane systems (csms) and putative surface adherence protein regions (sapr) have been reported to be responsible $(39,110)$. The process generally, involves reversible attachment, irreversible attachment, maturation and dispersion. A. baumannii-associated infections are often contracted via biofilms on Foley catheters, venous catheters, or cerebrospinal shunts.

Hospital environment. $A$. baumannii is the most important bacterial species associated with nosocomial or hospitalacquired infections. These infections are caused by organisms present in hospitals or other clinical facilities. Most of these infections emerge while the patient is in the hospital but others are not detected until the patient has been discharged. In the early 70s, nosocomial pathogens were predominantly Gram-negative bacilli especially Ps. aeruginosa, and Enterobacteriaceae, while the 90s saw the emergence of Gram-positive methicillin-resistant $S$. aureus (MRSA) and vancomycin-resistant enterococci (VRE) $(111,115)$. In recent times however, in addition to MRSA and VRE (mainly in the USA), the introduction of broad spectrum antibiotics in hospitals has resulted in the emergence of multidrug resistant strictly Gram-negative nosocomial bacterial pathogens including Ps. aeruginosa, Klebsiella pneumonia and $A$. baumannii (33). In a hospital environment, they have been isolated from reusable medical equipments such as ventilator tubings, arterial pressure monitoring devices, humidifiers, washbasins, plastic urinals and respirometers $(26,52$, $112,118)$. The organisms have also been isolated from the skin of healthcare personnel, mattresses, pillows and in all types of ventilator equipment and moist situations such as sinks and tap water $(8,56)$. The presence of MDR and nosocomial Acinetobacter in the hospital environment complicates treatment since such infected patients often need to be isolated $(70,77)$. This underlies the need to fully study these organisms and proffer alternative chemotherapeutic solutions.

Though many Acinetobacter spp. are only found in certain habitats, some are distributed widely in nature. $A$. calcoaceticus is found in water and soil and on vegetables $(2,10)$.

\section{Diagnosis}

Infection or colonization with Acinetobacter is usually diagnosed by the culture of environmental and clinical samples. The environmental samples include wastewater, activated sludge, sewage, aquaculture freshwater habitats, frozen shrimps (49) soil (16, 112), vegetables (10), fresh and spoiled meat (34) animal droppings and river water while the clinical samples include blood, cerebrospinal fluid, endoctracheal aspirate, pus (91), sputum, urine, respiratory secretions (115), Catheter tips (24), wound, stool or sterile body fluid, skin, cordon of newborns, nasal swabs, hand swabs of hospital workers and hospital environments (swabs on surfaces of machines, wash-hand basins, floors, tables, UV lamps) (22). Microbiologic cultures can be processed by standard methods on routine media. Antimicrobial susceptibility can be determined by various means, with the agar-dilution method being the gold-standard.

A glance at the literature shows just how non fastidious and versatile Acinetobacters are in terms of growth on media. A wide range of media has been employed in cultivating organisms from different sources. For routine clinical and laboratory investigations, traditional methods have used agar (34), brain heart infusion agar (108), nutrient agar, tryptic soy agar (9), Simon's Citrate agar (29) Violet red bile agar, Luria Bertani agar (49) Eosin-methylene blue, MacConkey agar and Holton medium (34). For environmental screening, especially where Acinetobacter may be in very low numbers, Bauman's' Enrichment Medium has been employed $(13,49)$ and broths including MacConkey broth, trypton soy broth, Brain Heart Infusion broth (49) and Luria broth $(29,63)$. Highly contaminated samples are inoculated in a liquid mineral medium containing a single carbon source and ammonium or nitrate salt as the nitrogen source with the final $\mathrm{pH}$ of the medium being 5.5 to 5.6 (63). Shaking during the incubation is employed in order for the strictly aerobic acinetobacters to outgrow pseudomonads. The broths can later be transferred onto Eosin-methylene blue, MacConkey agar or a selective medium such as Herellea agar or Leeds Acinetobacter Medium in which antibiotics have been added to suppress the growth of other bacteria $(51,108)$.

Biochemical typing methods include the use of colorimetric based GN card ID 32 GN, API 20NE, RapID NF Plus and Vitek 2 systems (19) all of which are antibody-based agglutination tests. Serological identification has been attempted with the analysis of capsular type and lipopolysaccharide (98) molecules as well as protein profiles for taxonomy and epidemiological investigations.

Because of the widespread nature of Acinetobacter spp., typing methods are required for genomic characterization (49). The differences in antimicrobial efficacy against different species, and the need to select effective chemotherapeutic agents, require the accurate identification of Acinetobacter spp. to the species level. Thus several molecular diagnostic methods including the polymerase chain reaction (PCR) (47), PFGE, RAPD-PCR DNA fingerprinting $(16,86)$, fluorescent in situ hybridization (FISH) (112), 16S rRNA gene restriction analysis (ARDRA) (79), and 16S rRNA gene PCR-DGGE fingerprinting for genetic characterization of Acinetobacter spp. from environmental samples Vanbroekhoven et al. have been employed (112). A recent diagnostic method which was reported to have high specificity and can discriminate between Acinetobacter species is the microsphere-based array technique that combines an allelespecific primer extension assay and microsphere hybridization (73). The method was reported to be so efficient that 13 different species of Acinetobacter were discriminated in less than $9 \mathrm{~h}$ with $90 \%$ accuracy and precision (73). The use of DNA-DNA hybridization and sequence analysis (19, 49 ) is considered the gold standard, but the method is laborintensive and impractical in most clinical laboratories.

Other methods that have been employed in the epidemiological investigation of outbreaks caused by Acinetobacter spp. include biotyping, phage typing, cell envelope protein typing, plasmid typing, ribotyping, restriction fragment length polymorphisms and arbitrarily primed PCR (AP-PCR) (4). These methods are however too expensive and too technical for use in unequipped laboratories. Exploration of sim- 
ple laboratory culture procedures will enhance isolation of these organisms especially in developing countries where electricity and sophisticated diagnostic procedures, and trained manpower are lacking.

\section{Factors predisposing individuals to acinetobacterioses}

Though it is generally agreed that $A$. baumannii is the most medically significant Acinetobacter spp., there is an ongoing debate on the clinical impact of the Acinetobacters with controversial views on whether these organisms increase morbidity or mortality. While some researchers are of the opinion that A. baumannii infections are responsible for an increase in patient mortality, others are of the opinion that infections occur in critically ill patients and mortality is as a result of other underlying diseases $(28,35,36)$. Whatever the case may be, virtually every study has concluded that there is a detrimental effect (45). The lack of a consensus on the degree of mortality may be due in part to the difficulty in distinguishing between colonization and infection, which is compounded by limited information on the pathogenesis. There is also extensive methodological heterogeneity between studies (prospective versus retrospective), and variation in the definitions of cases versus controls (A. baumannii infection versus other infection, polymicrobial versus monomicrobial) $(48,70)$. There are also problems with the accurate identification of organisms to the species level as well as assessment of the impact of specific clones, which may differ in virulence potential (45). In addition, the ability of organisms to rapidly develop multidrug resistance and to persist in harsh environmental conditions calls for the need to take Acinetobacter infections seriously.

Individuals vulnerable to Acinetobacter infections include those who have recently undergone major surgery, those with malignant diseases or burns, and immunosuppressed patients such as the elderly, neonates with low birth weights, and patients with prolonged illnesses $(84,107,108)$. Nosocomial pneumonia occur in intensive care units (ICUs) with a frequency of 3 to $5 \%$ (even higher in patients with mechanical ventilation) and with crude mortality rates of 30 to $75 \%$ have been reported $(107,108)$. Bacteremia is very common in elderly immunocompromised patients. The main source of bacteremia in these patients is bacterial pneumonia, and the most important predisposing factors are malignant diseases, trauma, prolonged antibiotic treatment, prolonged intravenous lines, post operations, urinary catheterization, renal transplants chest tubes, mechanical ventilation, parenteral nutrition and long hospitalization $(64,82)$. Poor hygienic conditions, and contaminated food and water are common sources of infection. In addition, it's been reported that lower temperatures and an acidic $\mathrm{pH}$ may enhance the ability of Acinetobacter spp. to invade dead tissues (58).

\section{Treatment, prevention and control}

Treatment of Acinetobacter infections should be individualized according to susceptibility patterns as the carbapenems, some fluoroquinolones and doxycycline may retain activity. Impenim with an aminoglycoside and $\beta$-lactam $/ \beta$-lactamase inhibitor with an aminoglycoside was found to be synergistic in vivo. Quinolone and amikacin synergy was also observed. The treatment of a serious infection with Acinetobacter should be combination therapy based on laboratory antimicrobial susceptibility results. Local antimicrobial prescribing habits should be critically guided by the susceptibility results. Suspected hospital outbreaks involving multidrug-resistant Acinetobacter infections should not be regarded with akinesis but be tackled ferociously and promptly. The prompt revision of infection control procedures such as hand-washing, patient isolation, ventilator care and good housekeeping is also pertinent. Chemotherapeutic approaches for most antimicrobialresistant Gram-negative infections, include the use of carbapenems (imipenem and meropenem), but carbapenemresistant Acinetobacter is increasingly reported $(56,101)$. Resistance to the carbapenem class of antibiotics complicates the treatment of multidrug-resistant Acinetobacter infections. However, colistin and polymyxin B have been used to treat highly resistant Acinetobacter infections; unfortunately renal toxicity of colistin has made its choice unattractive. Acinetobacter isolates resistant to colistin and polymyxin B have also been reported (44). The best approach is combination therapy where studies have demonstrated in vitro susceptibility of multidrug-resistant Acinetobacter to various synergistic combinations of antimicrobials including carbapenems, colistin, rifampin, and ampicillin-sulbactam $(67,101,121)$. The clinical utility of these combinations against pan-resistant Acinetobacter remains to be determined $(44,56,120)$.

The costs associated with controlling an outbreak of Acinetobacter infections can be staggering, and some institutions have even been forced to close entire units in order to interrupt the transmission of Acinetobacter $(64,104,109)$. Therefore, there is a very compelling need to prevent transmission in the healthcare setting and keep the organism from becoming endemic in an institution. It is also important that contamination of the environment, water or food should be guarded against especially by MDR strains. Careful personal and hand-hygiene should be observed. The disinfection of hands with-alcohol based disinfectants and observation of standard hospital practices cannot be overemphasized. Laboratories should embark on active surveillance to detect cultures and patients who are colonized with multidrugresistant Acinetobacter as well as a community-based surveillance to determine carriage rates. Other measures successful in the control of outbreaks include isolation precautions for infected or colonized patients, cohorting of patients, patients' relatives and staff, environmental disinfection, antimicrobial control, and unit closure $(105,118)$. Investigations for novel antibiotic substances with possible activity against Acinetobacter spp. from plants and other natural sources with a view to sourcing alternative treatment should be seriously considered by both research institutions and pharmaceutical companies.

\section{Conclusion}

Acinetobacter previously ignored as low-grade pathogens have suddenly generated interest. The emergence of multiresistant strains, some of which are pan-resistant to antibiot- 
ics, that suddenly cause an outbreak of infection, and the ability of the organism to resist desiccation and its rapid transformation potential has overwhelmed scientists worldwide. Despite an exponential rise in A. baumannii infections over the past decade, many questions remain unanswered (45). While knowledge of the virulence and particularly the resistance mechanisms is increasing, the populations at risk and the pathogenesis of severe infection are still poorly understood. The association of the organisms with conditions such as bacteraemia or pulmonary infections, diarrhea and nosocomial infections further highlights a major concern. Most available reports are on $A$. baumannii as the most important clinical species, while investigations are concentrated more on clinical samples. Other samples including environmental and food samples should be investigated for both $A$. baumannii and other species with a view to investigating their health implications. Control measures should not be limited to investigations of the environment (food, water etc.) for microbial characterization and studies of Acinetobacter virulence and resistance mechanisms alone but the use of animal models should also be considered. The dearth of available treatments remains a major concern and although further work on the use and efficacy of combination therapies is warranted, a more urgent priority must be the development of novel therapeutic agents (45) including studies on the effect of phytochemicals from plant sources (32).

\section{Acknowledgements}

This study was supported by Cape Peninsula University of Technology, Cape Town South Africa (research fund RP03).

\section{References}

1. Allen, D., and B. Hartman. 2000. Acinetobacter Species, p. 215 324. In Mandell, G.L., J.E. Bennett, R. Dolin (ed.), Principles and Practice of Infectious Diseases. Churchill Livingstone, Philadelphia, USA.

2. Barbe, V., D. Vallene, N. Fonknechten, et al. 2004. Unique features revealed by the genome sequence of Acinetobacter sp. ADP1, a versatile and naturally transformation competent bacterium. Nucleic Acids Res. 32:5766-5779.

3. Baumann, P., M. Doudoroff, and R.Y. Stanier. 1968. A study of the Moraxella group. II Oxidative-negative species (genus Acinetobacter). J. Bacteriol. 95:1520-1541.

4. Bello, H., G. Gonzalez, M. Dominguez, R. Zemelman, A. Garcia, and S. Mella. 1997. Activity of selected $\beta$-lactams, ciprofloxacin, and amikacin against different Acinetobacter baumannii biotypes from Chilean hospitals. Diagn. Microbiol. Infect. Dis. 28:183-186.

5. Bergobne-Bérézin, E. 1995. The increasing incidence of out breaks of Acinetobacter spp.: The need for control and new agents. J. Hosp. Infect. 30:441-452.

6. Bergobne-Bérézin, E., and K.J. Towner. 1995. Acinetobacter spp. as nosocomial pathogens: Microbiological and epidemiological features. Clin. Microbiol. Rev. 9:148-161.

7. Bergogne-Bérézin, E., and K.J. Towner. 1996. Acinetobacter spp. as nosocomial pathogens: Microbiological, clinical, and epidemiological features. Clin. Microbiol. Rev. 9:148-165.

8. Bergogne-Bérézin, E. 2001. The increasing role of Acinetobacter species as nosocomial pathogens. Curr. Infect. Dis. Rep. 3:440-444.

9. Bergogne-Bérézin, E. 2009. Importance of Acinetobacter spp. Acinetobacter biology and pathogenesis. Infect. Agents Pathol. 1-18.

10. Berlau, J., H. Aucken, M. Houang, and T.L. Epitt. 1999. Isolation of Acinetobacter spp. including A. baumannii from vegetables: Implications for hospital-acquired infections. J. Hosp. Infect. 42:201204.
11. Blanco, M., J.E. Blanco, A. Mora, et al. 2003. Serotypes, virulence genes, and intimin types of shiga toxin (verotoxin)-producing Escherichia coli Isolates from healthy sheep in Spain. J. Clin. Microbiol. 41:1351-1356.

12. Bouvet, P., and P. Grimont. 1986. Taxonomy of the genus Acinetobacter with the recognition of Acinetobacter baumanni sp. nov., Acinetobacter haemolyticus sp. nov., Aninetobacter johnsonii sp. nov., and amended description of Acinetobacter calcoaceticus and Acinetobacter lwofii. Int. J. Syst. Bacteriol. 36:228-240.

13. Bouvet, P.J.M., and M.L. Joly-Guillou. 2000. Acinetobacter spp. p. 34-86. In J. Freney, F. Renaud, W. Hansen, and C. Bollet (ed.), Summary of Clinical Bacteriology. Eska, Paris.

14. Braun, G. 2009. Acinetobacter biology and pathogenesis. Infect. Agents. Pathol. 1-10.

15. Brisou, J. 1957. Contribution á l'étude des Pseudomonadaceae Précisions taxonomiques sur le genre Acinetobacter. Ann. Inst. Pastuer. 93:397-404.

16. Carr, E., H. Eason, S. Feng, A. Hoogenraad, R. Croome, J. Soddell, K. Lindrea, and R. Seviour. 2001. RAPD-PCR typing of Acinetobacter isolates from activated sludge systems designed to remove phosphorus microbiologically. J. Appl. Microbiol. 90:309319.

17. Castellanos, M.E., M.T. Asensio, V.R. Blanco, M.R. Suarez, A.M. Torrico, and A.C. Llosa. 1995. Infective endocarditis of an intraventricular patch caused by Acinetobacter haemelyticus. Infect. 23:243-245.

18. Chen, M.Z., P.R. Hsueh, L.N. Lee, C.L. Yu, P.C. Yang, and K.T. Luh. 2001. Severe community acquired pneumonia due to Acinetobacter baumannii. Chest. 120:1072-1077.

19. Chen, T., L. Siu, Y. Lee, C. Chen, L. Huang, R.C. Wu, W. Cho, and C. Fung. 2008. Acinetobacter baylyi as a pathogen for opportunistic Infection. J. Clin. Microbiol. 46:2938-2944.

20. Choi, C.H., J.S. Lee, Y.C. Lee, T.I. Park, and J.C. Lee. 2008. Acinetobacter baumannii invades epithelial cells and outer membrane protein A mediates interactions with epithelial cells. BMC Microbiol. 8:216.

21. Choi, C.H., E.Y. Lee, Y.C. Lee, T.I. Park, H.J. Kim, S.H. Hyun, S.A. Kim, S.K. Lee, and J.C. Lee. 2005. Outer membrane protein 38 of Acinetobacter baumannii localizes to the mitochondria and induces apoptosis of epithelial cells. Cell Microbiol. 7:1127-1138.

22. Constantiniu, S., A. Romaniuc, L.S. Iancu, R. Filimon, and J. Taraşi. 2004. Cultural and biochemical characteristics of Acinetobacter spp. strains isolated from hospital units. J Prev. Med. 12:35-42.

23. Corbella, X., M. Pujol, and J. Ayats. 1996. Relevance of digestive tract colonization in the epidemiology of nosocomial infections due to multi-resistant Acinetobacter baumannii. Clin. Infect. Dis. 23:329334.

24. Costa, G.F.M., M.C.B. Tognim, C.L. Cardoso, F.E. CarraraMarrone, C. Marrone, and L.B. Garcia. 2006. Preliminary evaluation of adherence on abiotic and cellular surfaces of Acinetobacter baumannii strains isolated from catheter tips. Braz J. Infect. Dis. 10:346-351.

25. Crawford, P.M., M.D. Conway, and G.A. Peyman. 1997. Traumainduced Acinetobacter lwoffi endophthalmitis with muli-organism occurrence: Strategies with intra-vitreal treatment. Eye. 11:863-864.

26. Cunha, B., J. Klimek, J. Gracewski, J. McLaughlin, and R. Quitiliani. 1980. A common source outbreak of pulmonary Acinetobacter iinfections traced to Wright respirometers. Postgrad. Med. J. 56:169-172.

27. De Bord, G. 1939. Organisms invalidating the diagnosis of gonorrhea by the smear method. J. Bacteriol. 39:119.

28. Dijkshoorn, L., A. Nemec, and H. Seifert. 2007. An increasing threat in hospitals: Multi-drug resistant Acinetobacter baumannii. Nat. Rev. Microbiol. 5:939-951.

29. Dorsey, C.W., A.P. Tomaras, P.L. Connerly, M.E. Tolmasky, J.H. Crosa, and L.A. Actis. 2004. The siderophore-mediated iron acquisition systems of Acinetobacter baumannii ATCC 19606 and Vibrio anguillarum 775 are structurally and functionally related. Microbiol. 150:3657-3667.

30. Doughari, J.H., P.A. Ndakidemi, I.S. Human, and S. Benade. 2010. Verocytotoxic diarrhogenic bacteria and food and water contamination in developing countries: A challenge to the scientific and health community. Rev. Infect. 1:202-210.

31. Doughari, J.H., P.A. Ndakidemi, I.S. Human, and S. Bennade. 2009a. Shiga toxins (Verocytotoxins). Afr. J. Microbiol. Res. 3:681693. 
32. Doughari, J.H., P.A. Ndakidemi, I.S. Human, and S. Bennade. 2009b. Phytochemicals as chemotherapeutic agents and antioxidants: Possible solution to the control of antibiotic resistant verocytotoxin producing bacteria. J. Med. Plants Res. 3:839-848.

33. Endimiani, A., F. Luzzaro, R. Migliavacca, E. Mantengoli, A. Hujer, K. Hujer, L. Pagani, R. Bonomo, G. Rossolini, and A. Toniolo. 2007. Spread in an Italian hospital of a clonal Acinetobacter baumanni strain producing the TEM-92 extended-spectrum $\beta$-lactamase. Antimicrob. Agents. Chempther. 51:2211-2214.

34. Eribo, B., and J.M. Jay. 1985. Incidence of Acinetobacter spp. and other Gram-negative, Oxidase-negative bacteria in fresh and spoiled ground beef. Appl. Environ. Microbiol. 49:256-257.

35. Falagas, M.E., I.A. Bliziotis, and I.I. Siempos. 2006. Attributable mortality of Acinetobacter baumannii infections in critically ill patients: A systematic review of matched cohort and Case-control studies. Critical Care. 10:48-55.

36. Falagas, M.E., and I.A. Bliziotis. 2007. Pandrug-resistant Gramnegative bacteria: The dawn of the post-antibiotic era? Int. J. Antimicrob. Agents. 29:630-636.

37. Fournier, P.E., D. Vallenet, V. Barbe, et al. 2006. Comparative genomics of multidrug resistance in Acinetobacter baumannii. PLoS Gen. 2:7.

38. Francey, T., F. Gaschen, J. Nicolet, and A.P. Burnens. 2000. The role of Acinetobacter baumannii as nosocomial pathogen for dogs and cats in intensive care unit year. J. Vet. Int. Med. 14:177-183.

39. Gaddy, J.A., and L.A. Actis. 2009. Regulation of Acinetobacter baumannii biofilm formation. Future Microbiol. 4:273-278.

40. Gallego, L., and K.J. Towner. 2001. Carriage of class 1 integrons and antibiotic resistance in clinical isolates of Acinetobacter baumannii from northern Spain. J. Med. Microbiol. 50:71-77.

41. Garcia, A., H. Solar, C. Gonzalez, and R. Zemelman. 2000. Effect of EDTA on the resistance of clinical isolates of Acinetobacter baumannii to the bactericidal activity of normal human serum. J. Med. Microbiol. 49:1047-1050.

42. Gerischer, U. 2008. Acinetobacter spp. p. 101-108. In U.V Gerischer, L. Mukua, and K. Mirgja (ed.). Acinetobacter Molecular Biology. Caister Acad. Press, Norfolk, UK.

43. Ghigliazza, R., A. Lodi, and M. Rovatti. 1998. Study on biological phosphorus removal process by Acinetobacter lwoffi: Possibility to by-pass the anaerobic phase. Bioprocess Eng. 18:207-211.

44. Giamarellos-Bourboulis, E.J., E. Xirouchaki, and H. Giamarellou. 2001. Interactions of colistin and rifampin on multidrug-resistant Acinetobacter baumannii. Diagn. Microbiol. Infect. Dis. 40:117-120.

45. Gordon, N.C., and D.W. Wareham. 2010. Multidrug-resistant Acinetobacter baumannii: Mechanisms of virulence and resistance. Int. J. Antimicrob. Agents. 35:219-226.

46. Grehn, M., and A. von Graevetnitz. 1978. Search for Acinetobacter calcoaceticus subsp. anitratus: Enrichment of faecal samples. J. Clin. Microbiol. 8:342-343.

47. Grotiuz, G., A. Sirok, P. Gadea, G. Varela, and F. Schelotto. 2006 Shiga toxin 2-producing Acinetobacter haemolyticus associated with a case of bloody diarrhea. J. Clin. Microbiol. 44:3838-3841.

48. Grupper, M., H. Sprecher, T. Mashiach, and R. Finkelstein. 2007. Attributable mortality of nosocomial Acinetobacter bacteremia. Infect. Control Hosp. Epidemiol. 28:293-298.

49. Guardabassi, L., A. Dalsgaard, and J.E. Olsen. 1999. Phenotypic characterization and antibiotic resistance of Acinetobacter spp. isolated from aquatic sources. J. Appl. Microbiol. 87:659-667.

50. Heidelberger, M., A. Das, and E. Juni. 1969. Immunochemistry of the capsular polysaccharide of an Acinetobacter. Pub. Nat. Acad. Sci. 63:47-50.

51. Holton, J. 1983. A note on the preparation and use of selective medium for the isolation of Acinetobacter spp. From clinical sources. J. Appl. Bacteriol. 54:141-142.

52. Horrevorts, A., K. Bergman, L. Kollee, I. Breuker, I. Tjernberg, and L. Dijkshoorn. 1995. Clinical and epidemiological investigations of Acinetobacter genomospecies 3 in neonatal intensive care unit. J. Clin. Microbiol. 3:1567-1572.

53. Hoštacká, A., and L.' Klokočníková. 2002. Characteristics of clinical Acinetobacter spp. Strains. Folia Microbiologica. 47:579582.

54. Houang, E.T.S., R.T. Sormunen, L. Lai, C.Y. Chan, and A.S.Y. Leong. 1998. Effect of desiccation on the ultrastructural appearances of Acinetobacter baumannii and Acinetobacter lwoffii. J. Clin. Microbiol. 51:786-788.

55. Janssen, P., R. Maquelin, R. Coopman, I. Tjernberg, and P. Bouvert. 1997. Determination of Acinetobacter genomic species by AFLP finger printing. Int. J. Syst. Bacteriol. 47:1179-1187.
56. Jain, R., and L.H. Danziger. 2004. Multi-drug resistant Acinetobacter infections: An emerging challenge to clinicians. Ann. Pharmacother. 38:1449-1459.

57. Jawad, A., A.M. Snelling, J. Heritage, and P.M. Hawkey. 1998 Exceptional desiccation tolerance of Acinetobacter radioresistens. J. Hosp. Infect. 39:235-240.

58. Joly-Guillou, M.L. 2005. Clinical impact and pathogenicity of Acinetobacter. Eur. Soc. Clin. Microbiol. Infect. Dis. 11:868-873.

59. Juni, E. 1984. Genus III. Acinetobacter brisou et prévot. 1954. p. 303-307. In: N. Krieg, and J. Holt (ed.), Bergy's Manual of Systemic Bacteriology, vol 1. The Williams and Wilkins Co., Baltimore, USA.

60. Kaplan, N., E. Rosenberg, B. Jann, and K. Jann. 1985. Structural studies of the capsular polysaccharide of Acinetobacter calcoaceticus BD4. Eur. J. Biochem. 152:453-458.

61. King, L.B., E. Swiatlo, A. Swiatlo, and L.S. McDaniel. 2009. Serum resistance and biofilm formation in clinical isolates of Acinetobacter baumannii. FEMS Immunol. Med. Microbiol. 55:414-421.

62. Knapp, S., C.W. Wieland, S. Florquin, R. Pantophlet, L. Dijkshoorn, N. Tshimbalanga, S. Akira, and T. van der Poll. 2006. Differential roles of CD14 and toll-like receptors 4 and 2 in murine Acinetobacter pneumonia. Am. J. Resp. Critic Care Med. 173:122-129.

63. Koneman, E.M.D., and S.M.D. 1997. Acinetobacter characteristics. p. 332-415. In W.M. Allen, P.C. Janda, W.M.D. Schreckenberger, and D. Winn Jr (ed.), Color Atlas and Text Book of Diagnostic Microbiology. Fifth edition. Lippincott Williams and Wilkins, New York, USA.

64. Kurcik-Trajkovska, B. 2009. Acinetobacter spp.-a serious enemy threatening hospitals worldwide. Macedonian. J. Med. Sci. 2:157162.

65. Lambert, T., D.M. Gerbaud, M. Galimand, and P. Caurvalin. 1993. Characterization of Acinetobacter haemolyticus aac(6')-Ig gene encoding an aminoglycoside 6- $N$-acetyltransferase which modifies amikacin. Antimicrob. Agents Chemother. 37:2093-2100.

66. Landman, D.C., C. Georgescu, D. Martin, and J. Quale. 2002. Polymixins revisited. Clin. Microbiol. Rev. 21:449-465.

67. Landman, D., J.M. Quale, D. Mayonga, A. Adedeji, K. Vangala, and J. Ravishankar. 2002. City ward clonal outbreak of multi-resistant Acinetobcter baumanni and Pseudomonas aeruginosa in Brooklyn NY: The pre-antibiotic era has returned. Arch. Int. Med. 162:15151520 .

68. La Scola, B., and D. Raoult. 2004. Acinetobacter baumannii in human body louse. Emerg Infect. Dis. 10:1671-1673.

69. Lee, H.W., Y.M. Kah, J. Kim, J.C. Lee, S.Y. Seol, and D.T. Cho. 2008. Capacity of multi-drug resistant clinical isolates of Acinetobacter baumannii to form biofilm and adhere to epithelial cell surfaces. Clin. Microbiol. Infect. 14:49-54

70. Lee, N.Y., H.C. Lee, N.Y. Ko, C.M. Chang, H.I. Shih, C.J. Wu, and W.C. Ko. 2007. Clinical and economic impact of multidrug resistance in nosocomial Acinetobacter baumanni bacteremia. Infect. Control Hosp. Epidemiol. 28:713-719.

71. Lessel, E. 1971. Minutes of the subcommittee on the taxonomy of Moraxella and allied bacteria. Inter. J. Syst. Bacteriol. 21:213-214.

72. Lesouhaitier, O., W. Veron, A. Chapalain, A. Madi, A. Blier, A Dagorn, N. Connil, S. Chevalier, N. Orange, and M. Feuilloley. 2009. Gram-negative bacterial sensors for eukaryotic signal molecules. Sensors. 9:6967-6990.

73. Lin, Y., W. Sheng, S. Chang, J. Wang, Y. Chen, R. Wu, K. Hsia, and S. Li. 2008. Application of microsphere-based array for rapid identification of Acinetobacter spp. with distinct antimicrobial susceptibilities. J. Clin. Microbiol. 46:612-617.

74. Mandri, T., and J. Lin. 2007. Isolation and characterization of engine oil degrading indigenous microrganisms in Kwazulu-Natal, South Africa. Afr. J. Biotechnol. 6:023-027.

75. Margesin, R., D. Labbé, F. Schinner, C.W. Greer, and L.G. Whyte 2003. Characterization of hydrocarbon-degrading microbial populations in contaminated and pristine alpine soils. Appl. Environ. Microbiol. 69:3085-3092.

76. Martinez, M.A., M.E. Pinto, R. Zemelman, L.A. Cifras, G. Lira and C. Ramirez. 1998. Surface characteristics and antimicrobial sensitivity of clinical strains of Acinetobacter spp. Rev. Med. Chile. 126:1079-1084.

77. McGowan, J.E. 2006. Resistance in non fermenting Gram-negative bacteria: Multidrug resistance to the maximum. Am. J. Med. 119:S29-S36.

78. Mihara, K., T. Tanabe, Y. Yamakawa, T. Funahashi, H. Nakao, S. Narimatsu, and S. Yamamoto. 2004. Identification and transcriptional organization of a gene cluster involved in biosynthesis and transport of acinetobactin, a siderophore produced by Acinetobacter baumanni ATCC $19606^{\mathrm{T}}$. Microbiology 150:2587. 
79. Nemec, A., L. Dijkshoorn, and P. Jezek. 2000. Recognition of two novel phenons of the genus Acinetobacter among non-glucoseacidifying isolates from human specimens. J. Clin. Microbiol. 38:3947-3951.

80. Nichols, H.A., and D.W. Osborn. 1979. Bacterial stress prerequisite for biological removal of phosphorus. J. Water Pollut. Control Fed. 51:557-569.

81. Oberoi, A., A. Aggarwal, and M. Lal. 2009. A decade of an underestimated nosocomal pathogen-Acinetobacter in a tertiary care hospital in Punjab. Jkscience. 11:24-26.

82. OECD. 2008. Consensus document on information used in the assessment of environmental applications involving Acinetobacter. OECD Environment, Health and Safety Publications Series on Harmonisation of Regulatory Oversight in Biotechnology. ENV/JM/ MONO. No. 46:37

83. Okabe, S., M. Oshiki, Y. Kamagata, et al. 2010. A great leap forward in microbial ecology. Microbes Environ. 25:230-240.

84. Peleg, A.Y., S. Jara, D. Monga, G.M. Eliopoulos, C. Robert, Jr. Moellering, and E. Mylonakis. 2009. Galleria mellonella as a model system to study Acinetobacter baumannii. Pathogenesis and therapeutics. Antimicrob. Agents Chemother. 53:2605-2609.

85. Peleg, A., H. Seifert, and D. Paterson. 2008. Acinetobacter baumannii: Emergence of a successful pathogen. Clin. Microbiol. Rev. 21:538-582.

86. Peleg, A.Y., B.A. Potoski, R. Rea, J. Adams, J. Sethi, B. Capitano, S. Husain, E.J. Kwak, S.V. Bhat, and D.L. Paterson. 2007. Acinetobacter baumannii bloodstream infection while receiving tigecycline: a cautionary report. J. Antimicrob. Chemother. 59:128131.

87. Perez, F., A.M. Hujer, K.M. Hujer, B.K. Decker, P.N. Rather, and R.A. Bonomo. 2007. Global challenge of multidrug-resistant Acinetobacter baumannii. Antimicrob. Agents Chemother. 51:34713484.

88. Peterson, L. 2001. Quinolone molecular structure-activity relationship: What we have learned about improving antimicrobial activity. Clin. Infect. Dis. 33:S180-S186.

89. Phuong, K., K. Kakii, and T. Nikata. 2009. Intergeneric coaggregation of non-flocculating Acinetobacter spp. isolates with other sludgeconstituting bacteria. J. Biosci. Bioeng. 107:394-400.

90. Piéchaud, D., M. Piéchaud, and L. Second. 1956. Variéties protéolitiques de Moraxella lwofii et de Moraxella glucidolytica. Ann. Inst. Pastuer. 90:517-522.

91. Prashanth, K., and S. Badrinath. 2005. Epidemiological investigation of nosocomial Acinetobacter infections using arbitrarily primed PCR and pulse field gel electrophoresis. Indian J. Med. Res. 122:408418 .

92. Poirel, L., O. Menuteau, N. Agoli, C. Cattoen, and P. Nordmann. 2003. Outbreak of extended-spectrum beta-lactamase VEB-1producing isolates of Acinetobacter baumannii in a French hospital. J. Clin. Microbiol. 41:3542-3547.

93. Rathinavelu, S., Y. Zavros, and J.L. Merchant. 2003. Acinetobacter lwoffii infection and gastritis. Microbes Infect. 5:651-657.

94. Richet, H., and P.E. Fournier. 2006. Nosocomial infections caused by Acinetobacter baumannii: A major threat worldwide. Infect. Control Hosp. Epidemiol. 27:245-247.

95. Robinson, A., A.J. Brzoska, K.M. Turner, R. Withers, E.J. Harry, P.J. Lewis, and N.E. Dixon. 2010. Essential biological processes of an emerging pathogen: DNA replication, transcription, and cell division in Acinetobacter spp. Microbiol. Mol. Bio. Rev. 74:273-297.

96. Rodríguez-Hernández, M.J., J. Pachón, C. Pichardo, L. Cuberos, J. Ibáñez-Martínez, A., García-Curiel, F. Caballero, I. Moreno, and M. Jiménez-Mejías. 2000. Impenem, doxycyclin, and amikacin in monotherapy and in combination in Acinetobacter baumanni experimental pneumonia. J. Antimicrob. Chemother. 45:493-501.

97. Rossau, R., M. Vanlandschoot, M. Gillis, and J. Deey. 1991. Taxonomy of Moraxellaceae $\backslash$ fam. nov., a new bacterial family to accommodate the genera Moraxella, Acinetobacter, and Psychrobacter and related organisms. Int. J. Syst. Bacteriol. 41:310-319.

98. Russo, T.A., N.R. Luke, J.M. Beanan, R. Olson, S.L. Sauberan, U.C. MacDonald, L.W. Schultz, T.C. Umland, and A.A. Campagnari. 2010. The K1 capsular polysaccharide of Acinetobacter baumannii Strain 307-0294 is a major virulence factor. Infect. Immun. 78:39934000.

99. Saint, N., C.E. Hamel, E. De, and G. Molle. 2000. Ion channel formation by N-terminal domain: A common feature of OprFs of Pseudomonas and OmpA of Escherichia coli. FEMS Microbiol. Lett. 190:261-265.
100. Sauer, K., A.H. Rickard, and D.G. Davies. 2007. Biofilms and biocomplexity. Microbe. 2:347-353.

101. Savov, E., D. Chankova, R. Vatcheva, and N. Dinev. 2002. In vitro investigation of the susceptibility of Acinetobacter baumannii strains isolated from clinical specimens to ampicillin/sulbactam alone and in combination with amikacin. Int J. Antimicrob. Agents. 20:390-392.

102. Schreckenberger, P., M. Daneshvar, R. Weyant, and D. Hollis. 2003. Acinetobacter, Achromobacter, Chryseobacterium, Moraxella and other non-fermentative Gram-negative rods. p. 86-99. In Murray, P., Baron, E., Jorgensen, J., Pfaller, M. and Yolken, R. (ed.), Manual of Clinical Microbiology. ASM Press, Washington D.C., USA.

103. Seifert, H., L. Dijkshoorn, P. Gerner-Smidt, N. Pelzer, I. Tjernberg, and M. Vaneechoutte. 2007. Distribution of Acinetobacter species on human skin: Comparison of phenotypic and genotypic identification methods. J. Clin. Microbiol. 35:2819-2825.

104. Siau, H., K.Y. Yuen, P.L. Ho, S.S. Wong, and P.C. Woo. 1999. Acinetobacter bacteremia in Hong Kong: Prospective study and review. Clin. Infect. Dis. 28:26-30.

105. Simor, A.E., M. Lee, M. Vearncombe, L. Jones-Paul, C. Barry, and M. Gomez. 2002. An outbreak due to multiresistant Acinetobacter baumannii in a burn unit: Risk factors for acquisition and management. Infect. Control Hosp. Epidemiol. 23:261-267.

106. Smith, M.G., T. Glanoulis, S. Pukatzki, J. Mekalanos, L. Ornston, M. Gertstein, and M. Snyder. 2007. New insights into Acinetobacter baumanni pathogenesis revealed by high-density pyrosequencing and transposon mutagenesis. Genes Dev. 21:601-614.

107. Torres, A., R. Aznar, J.M. Gatell, P. Jiminez, J. Gonzales, A. Ferrer, R. Celis, and R. Rodrigues-Roisin. 1990. Incidence risk and prognosis factors of nosocomial pneumonia in mechanically ventilated patients. Am. Rev. Resp. Dis. 142:522-528.

108. Towner, K. 2006. The genus Acinetobacter. Prok. 6:746-758.

109. Urban, C., S. Segal-Maurer, and J.J. Rahal. 2003. Considerations in control and treatment of nosocomial infections due to multidrugresistant Acinetobacter baumannii. Clin. Infect. Dis. 36:1268-1274.

110. Valero, C., M. Fariñas, D. Gárcia-Palomo, J. Mazarrasa, and J. González-Macías. 1999. Endocarditis due to Acinetobacter lwoffi on native mitral valve. Int. J. Cardiol. 69:97-99.

111. Vallenet, D., P. Nordmann, V. Barbe, et al. 2008. Comparative analysis of Acinetobacters: Three genomes for three lifestyles. PLoS One 3:1805e.

112. Vanbroekhoven, K., A. Ryngaert, P. Wattiau, R. Demot, and D. Springael. 2004. Acinetobacter diversity in environmental samples by $16 \mathrm{~S}$ rRNA gene PCR-DGGE fingerprinting. FEMS Mibrobiol. Ecol. 50:37-50.

113. Vidal, R., M. Dominguez, H. Urrutia, H. Bello, G. Gonzalez, and A. Garcia. 1996. Biofilm formation by Acinetobacter baumannii. Microbios. 86:49-58.

114. Vila, J., S. Marti, and J. Sanchez-Cedespes. 2007. Porins, efflux pumps and multidrug resistance in Acinetobacter baumannii. J. Antimicrob. Chemother. 59:1210-1215.

115. Vila, J., A. Ribera, F. Marco, J. Ruiz, J. Mensa, J. Chaves, G. Hernandez, and M.T.J. De Anta. 2002. Activity of clinafloxacin, compared with six other quinolones, against Acinetobacter baumanni clinical isolates. J. Antimicrob. Chemother. 49:471-477.

116. Villegas, M.V., and A.I. Hartstein. 2003. Acinetobacter outbreaks, 1977-2000. Infect. Control Hosp. Epidemiol. 24:284-295.

117. Weinstein, R.A. 1998. Nosocomial infection update. Emerg. Infect. Dis. 4:415-420.

118. Wendt, C., B. Dietze, E. Dietz, and H. Ruden. 1997. Survival of Acinetobacter baumannii on dry surfaces. J. Clin. Microbiol. 35:1394-1397.

119. Wisplinghoff, H., T. Bischoff, S.M. Tallent, H. Seifert, R.P. Wenzel, and M.B. Edmond. 2004. Nosocomial bloodstream infections in US hospitals: Analysis of 24,179 cases from a prospective nationwide surveillance study. Clin. Infect. Dis. 39:309-317.

120. Yoon, J., C. Urban, C. Terzian, N. Mariano, and J.J. Rahal. 2004. In vitro double and triple synergistic activities of Polymyxin B, imipenem, and rifampin against multidrug-resistant Acinetobacter baumannii. Antimicrob. Agents Chemother. 48:753-757.

121. Yu, H.B., Y.L. Zhang, Y.L. Lau, F. Yao, S. Vilches, S. Merino, J.M. Tomas, S.P. Howard, and K.Y. Leung. 2005. Identification and characterization of putative virulence genes and gene clusters in Aeromonas hydrophila PPD134/91. Appl. Environ. Microbiol. 71: 4469-4477.

122. Zanaroli, G., S. Di Toro, D. Todaro, G.C. Varese, A. Bertolotto, and F. Fava. 2010. Characterization of two diesel fuel degrading microbial consortia enriched from a non acclimated, complex source of microorganisms. Microb. Cell Fact. 9:1-13. 